American Journal of Pharmaceutical Education 2018; 82 (8) Article 6351.

\title{
RESEARCH
}

\section{Stress, Satisfaction, and Competency of Hospital Pharmacy Preceptors under the New Pharmacy Program in South Korea}

\author{
Heenam Seo, PharmD, MS, ${ }^{\text {a,b }}$ Kyungwoo Ryu, BPharm, ${ }^{\text {a }}$ Subin Lee, PharmD, ${ }^{\text {a }}$ Jinyong Noh, BPharm, \\ Hyeno La, PhD, ${ }^{\mathrm{d}}$ Eunyoung Kim, PharmD, $\mathrm{PhD}^{\mathrm{a}, \mathrm{c}}$ \\ ${ }^{a}$ Clinical Research Laboratory College of Pharmacy, Chung-Ang University, Seoul, South Korea \\ ${ }^{\mathrm{b}}$ Department of Pharmacy, Kangbuk Samsung Hospital, Seoul, South Korea \\ ${ }^{c}$ Division of Licensing of Medicines and Regulatory Science, The Graduate School Pharmaceutical Management, \\ Chung-Ang University, Seoul, South Korea \\ ${ }^{\mathrm{d}}$ College of Pharmacy, The Catholic University of Korea, South Korea \\ Submitted February 21, 2017; accepted May 8, 2017; published October 2018.
}

Objective. To evaluate hospital pharmacy preceptors' views of preceptorship and to explore the factors that might influence their stress and satisfaction after joining the newly implemented six-year pharmacy program in South Korea.

Methods. A nationwide, cross-sectional, self-administered 47-item online survey was conducted for preceptors at hospital pharmacy practice sites in 2015.

Results. Among 601 preceptors, 395 responded to the survey. They reported high stress and moderate role satisfaction and likelihood of continuing preceptorship. Workload was a major cause of stress and a barrier for continuing preceptorship, whereas improvement of professional knowledge and performance ability was considered the most important benefit and motivation of preceptorship. Monetary rewards were the most valuable incentive. Extra work hours used for precepting were a significant positive covariate for stress, while willingness to engage in preceptorship was a negative covariate for stress and positive covariate for satisfaction. Self-perceived assessments of preceptors' competencies showed moderate performance. Following an Importance-Performance Analysis (IPA), passion for teaching students and being a professional role model were identified as items in need of improvement. Conclusion. This study investigated relevant issues associated with hospital pharmacy preceptors in South Korea under the country's new experiential education program. The findings will help to enhance the quality of hospital pharmacy experiential education in countries that have implemented or are planning to implement a new pharmacy program.

Keywords: hospital pharmacy preceptor, experiential education, stress, satisfaction

\section{INTRODUCTION}

Experiential education (eg, clerkship experience) is an essential element in developing pharmacy students' abilities to apply theory to practice, problem solve, and acquire standard competencies as pharmacists. ${ }^{1}$ To achieve this goal, preceptors play crucial roles in pharmacy practice experience, as a teacher, mentor, and evaluator. They accomplish this by showing students how to apply knowledge gained in their didactic courses to actual clinical practice, by helping students engage in pharmacy activities, and by

Corresponding Author: Eunyoung Kim, Clinical Research Laboratory College of Pharmacy, Chung-Ang University, 84 Heukseok-ro, Dongjak-gu, Seoul 06974, South Korea.

Tel: +82-2-820-5791. Fax: +82-2-816-7338.

E-mail: eykimjcb777@cau.ac.kr assessing student performance and providing effective feedback. ${ }^{2,3}$ Thus, the recruitment and retention of qualified preceptors is essential to a successful experiential education system.

In South Korea, to balance the role of the pharmacist from a product-focused profession to a patient-focused one, the four-year curriculum system leading to a Doctor of Pharmacy (PharmD) degree was expanded to a six-year $(2+4)$ pharmacy education program. This change was implemented in 2009 to meet the global trend toward expanding pharmacy education curriculum. ${ }^{4}$ This new system recommends 800 hours of introductory pharmacy practice experience (IPPE) and 600 hours of advanced pharmacy practice experience (APPE). ${ }^{4}$ The Korean Association of Pharmacy Education (KAPE) stipulates experiential settings and requires a certain number of 


\section{American Journal of Pharmaceutical Education 2018; 82 (8) Article 6351.}

hours in each setting for IPPE as follows: 200 hours in community pharmacy, 400 hours in hospital pharmacy, 120 hours in pharmaceutical company, 20 hours in public service institute, and 60 hours in pharmacy college as introductory pharmacy practice. ${ }^{4}$ In contrast, for APPE, students must complete 600 hours but are given the option to choose one practice track among the clinical pharmacy track (hospital pharmacy, community pharmacy), industrial pharmacy track (pharmaceutical company), and pharmacy research track (pharmacy college). ${ }^{4}$ Experiential education began in 2014 .

To become a hospital pharmacy preceptor in South Korea, one must be approved by the Korean Accreditation Council for Pharmacy Education (KACPE). ${ }^{5}$ The requirements for hospital pharmacy preceptors include at least two years of practice experience to precept IPPEs, five years of practice experience, a master's degree, and a residency training in a relevant area to precept APPEs. ${ }^{5}$ Additionally, hospital pharmacy preceptors must complete an 8-hour preceptor development program created by KAPE and provided by KAPE-approved institutions. ${ }^{5}$ Preceptors are given the opportunity to practice experiencespecific learning objectives and to learn their role as mentor, role model and evaluator during the development education. For renewal of preceptorship, completing a minimum of 2 hours of training is required yearly. ${ }^{5}$ The incentives for preceptorship depend on colleges and hospitals. ${ }^{5}$ To provide students with individualized attention, a 1:2 preceptor-to-student ratio is recommended. ${ }^{5}$ However, variations in this ratio exist.

Among the sites, hospital pharmacies provide the longest duration of education, with 400 hours of IPPE (50\% of IPPE practice hours) to all students and 600 hours of APPE (100\% of APPE practice hours) to students who choose hospital pharmacy settings for their APPE. This may be because of their essential and exclusive activities to foster clinical pharmacists, such as participating in medical team activities (eg, nutritional support team, intensive care unit support team) and other advanced pharmacy services (eg, anticoagulant services, therapeutic drug monitoring).

Lee and colleagues reported that the job satisfaction of hospital pharmacists in South Korea was relatively low (2.47 on a 4 -point Likert scale). ${ }^{6}$ Hospital pharmacies experience chronic staff shortages and high turnover rates because of long hours (ie, hospital pharmacists have frequent night and weekend duties), low salary, and increased learning requirement for advanced pharmacist's role. ${ }^{7,8}$ Hospital pharmacists represent only $11.7 \%$ of actively practicing pharmacists, while community pharmacists represent $73.1 \% .{ }^{9}$ The number of students increased owing to the establishment of several new pharmacy colleges. ${ }^{10}$ For hospital pharmacists, pharmacy practice education may be a challenge that could lead to a decrease in preceptor enthusiasm for precepting students, and possibly affecting the quality of experiential education and increasing preceptor dropout.

At the outset of the newly implemented educational system, it is important to examine the environment at practice sites and to study preceptors' views regarding experiential education. Doing so could help develop strategies to support preceptors and increase their willingness and adherence to preceptorship.

\section{METHODS}

A nationwide, cross-sectional, self-administered online survey was conducted that targeted active hospital pharmacy preceptors, including coordinators from 63 hospital pharmacies, who participated in a survey of Korean Society of Health-System Pharmacists (KSHP) in 2014. ${ }^{11}$ Among all students who needed to take experiential education, $93.3 \%$ were covered by these 63 hospital pharmacies. Among 966 certified preceptors from these 63 hospitals, 835 active hospital pharmacy preceptors, including coordinators, were targeted to reflect real experiences. Certified preceptors who did not participate in experiential education were excluded. An email linked to the online survey was sent to pharmacy directors. They were asked if they wished to participate in the survey, and if so, to forward the email to all their active pharmacy preceptors and coordinators. Pharmacy directors were asked to reply to the questionnaire attached with an email regarding site information, such as location and size of the hospital, total number of preceptors, and rewards received from the pharmacy school and those provided to preceptors. Preceptors who provided informed consent could access the online survey. The data collection period was from May 4 to May 24, 2015. The modified Dillman method was used for the survey. ${ }^{12}$ The original email message and two follow-up reminders were sent to pharmacy directors at an interval of one week. The Institutional Review Board (IRB) of Chung-ang University approved the study protocol and all procedures conducted in this study prior to data collection.

The survey instrument was developed from literature reviews conducted by one professor and three clinical pharmacy researchers. ${ }^{5,13-19}$ It was pilot tested with 50 hospital pharmacy preceptors. Modifications for clarity of questions and response options were made based on the group's feedback. Internal consistency reliabilities (Cronbach's alpha) of the questions in the pilot test was 0.81 for the stress items, 0.83 for the benefits of precepting students, 0.94 for the importance of preceptors' competencies, and 0.91 for the performance of preceptors' competencies. The 


\section{American Journal of Pharmaceutical Education 2018; 82 (8) Article 6351.}

instrument consisted of 47 questions from six sections: demographic characteristics (20 questions), stress level and causes ( 7 questions), preceptor role satisfaction with and benefits of precepting (7 questions), valuable incentives (1 question), preceptor competencies (11 questions), and free text response on experiential education (1 question). Demographics consisted of two parts: general participant information, such as age and final degree, and experiential education specific information, such as the amount of extra time spent on teaching and the number of precepted students.

To explore factors that might influence preceptingrelated stress and satisfaction, a univariate analysis of preceptor demographic characteristics and preceptor stress or role satisfaction was performed, followed by a multivariate regression analysis with the identified significant variables.

To evaluate preceptors' self-perceived performance and to prioritize items for improvement among preceptor competencies, Importance-Performance Analysis (IPA) ${ }^{20}$ was conducted using the results of the importance and performance of preceptor competencies assessed by nine questions based on the preceptor roles recommended by the KAPE (Table 1). ${ }^{5}$ A 5-point Likert-type scale was used for rating the importance and performance of preceptors' competencies $(1=$ strongly disagree to $5=$ strongly agree $)$. The IPA is a two-dimensional grid used to measure attribute importance and performance, identify attributes that are doing well and those that need improvement, and help develop strategies for preceptor education. ${ }^{20}$ It has been widely used in service industries such as travel and tourism, education, and other sectors. ${ }^{21}$ Intersections in the IPA grid are made using total mean importance and performance of attributes, which divide it into four quadrants: (A) Concentrate Here, (B) Keep Up the Good Work, (C) Low Priority, and (D) Possible Overkill, to enable each mean of the attributes to be plotted into the grid for easy interpretation of the results. ${ }^{20}$

Except for demographic characteristics and the importance and performance of preceptors' competencies, preceptors were asked to choose one of five responses (strongly agree, agree, neither agree nor disagree, disagree, or strongly disagree) in most questions. Strongly agree and agree were considered as positive responses, while disagree and strongly disagree were considered as negative responses. Internal consistency reliabilities were reported as Cronbach's alpha. A Cronbach's alpha of at least 0.70 for each scale in the actual survey was considered desirable.

Descriptive statistics were examined using Excel 2010 (Microsoft Corporation, Redmond, WA). A univariate and multivariate regression analysis for identifying the factors influencing the stress and satisfaction of preceptors, IPA in preceptor competencies, and internal consistency reliability analysis were conducted using PASW Statistics 18.0 (IBM, Armonk, NY). Statistical significance was set at $p<.05$ for two-tailed tests.

\section{RESULTS}

Of the 63 hospitals, 36 participated in the survey (response rate $=57.1 \%$ ). Among the 601 preceptors identified from the 36 returned site questionnaires, 395 participated (response rate $=65.7 \%$ ). The 63 total and 36 participating hospitals were similar in size and location: with proportion of $\geq 900$ beds ( $24 \%$ vs $25 \%$ ), $500-899$ beds $(68 \%$ vs $67 \%$ ), and $<500$ beds (both $8 \%$ ); and $\geq 10$ million ( $37 \%$ vs $36 \%$ ), 1 million to 10 million ( $29 \%$ vs $28 \%$ ), and $\leq 1$ million ( $35 \%$ vs $36 \%$ ) in terms of location based on population. Respondents' general and experiential education-related demographics are listed in Tables 2 and $3 .{ }^{17}$ Gender, marital status, and employment status were also collected. The results showed high participation among females (95\%) and full-time employees (99\%). This may be because most $(>90 \%)$ hospital pharmacists in South Korea are females who work full-time. ${ }^{22}$ Marital status among participants was similar between single (51\%) and married (49\%).

The preceptors were asked whether stress increased from precepting students and, if so, to identify the top two

Table 1. Items Targeting Preceptors' Competencies

\begin{tabular}{ll}
\hline Item No. & \multicolumn{1}{c}{ Preceptors' Competencies } \\
\hline 1 & Understanding content, goals and evaluation of practice experience. \\
2 & Systemically organizing practice activities. \\
3 & Expressing enthusiasm for teaching. \\
4 & Tailoring contents of practice education to the level of the student. \\
5 & Being a role model in performing practice activities and solving problems. \\
6 & Providing sufficient opportunities to experience various aspects of pharmacy practice. \\
7 & Providing timely and constructive feedback. \\
8 & Helping students engage in pharmacy activities independently and improving their professional skills. \\
9 & Encouraging students to ask questions freely and responding to them positively.
\end{tabular}




\section{American Journal of Pharmaceutical Education 2018; 82 (8) Article 6351.}

Table 2. Participant Demographics and Characteristics $(\mathrm{N}=395)$

\begin{tabular}{|c|c|}
\hline Variables & No. $(\%)$ \\
\hline \multicolumn{2}{|l|}{ Age (yr) } \\
\hline $20-29$ & $89(23)$ \\
\hline $30-39$ & $197(50)$ \\
\hline$\geq 40$ & $109(27)$ \\
\hline \multicolumn{2}{|l|}{ Final degree $^{\mathrm{a}}$} \\
\hline $\mathrm{BS}$ & $234(59)$ \\
\hline MS & $146(37)$ \\
\hline $\mathrm{PhD}$ & $15(4)$ \\
\hline \multicolumn{2}{|c|}{ Years of hospital pharmacy experience } \\
\hline$\leq 5$ & $138(35)$ \\
\hline $6-10$ & $113(29)$ \\
\hline$\geq 11$ & $144(36)$ \\
\hline \multicolumn{2}{|l|}{ Position } \\
\hline Staff pharmacist & $211(53)$ \\
\hline Middle manager & $119(30)$ \\
\hline Manager & $65(17)$ \\
\hline \multicolumn{2}{|l|}{ Size of the site (beds) } \\
\hline $300-499$ & $34(9)$ \\
\hline $500-899$ & $159(40)$ \\
\hline$\geq 900$ & $202(51)$ \\
\hline \multicolumn{2}{|c|}{ Location of the site (population) } \\
\hline$<1$ million & $132(23)$ \\
\hline 1 million-10 million & $139(24)$ \\
\hline$>10$ million & $308(53)$ \\
\hline \multicolumn{2}{|l|}{ Annual income } \\
\hline$<\$ 50,000$ & $169(43)$ \\
\hline$\$ 50,000-\$ 70,000$ & $160(41)$ \\
\hline$>\$ 70,000$ & $65(17)$ \\
\hline \multicolumn{2}{|l|}{ Special certificate $^{\mathrm{b}}$} \\
\hline Yes & $91(23)$ \\
\hline No & $304(77)$ \\
\hline \multicolumn{2}{|l|}{ History of preceptorship ${ }^{c}$} \\
\hline Yes & $231(59)$ \\
\hline No & $164(42)$ \\
\hline
\end{tabular}

${ }^{\mathrm{a}} \mathrm{BS}=$ Bachelor of Science, $\mathrm{MS}=$ Master of Science, $\mathrm{PhD}=$ Doctor of Philosophy

${ }^{\mathrm{b}}$ Special certificates include Board of Pharmacy Specialties (BPS), Certificate of Pharmacy Specialties (CPS), and residency

${ }^{\mathrm{c}}$ History of preceptorship under four-year curriculum system or for residency

reasons. Sixty-five percent of the respondents $(n=258)$ answered that their stress increased from precepting students. Workload was ranked as the leading reason for stress followed by insufficient support (eg, staff, space, facilities) and self-study burden. Difficulty in schedule arrangements (eg, vacation) was the least common first reported source of stress $(2.3 \%)$, but it ranked the highest as the second reason for stress (31.8\%). Additionally, participants were instructed to report whether workload increased after joining pharmacy experiential education and, if so, how much overtime they worked each week. Sixty-eight percent of the respondents answered that their workload increased, and 70\% reported that they worked at least 1 hour of overtime per week. The median overtime work was 3 hours (range 1-25 hours). Table 4 presents the survey results on the causes of stress perceived by preceptors.

Preceptors were asked whether they were satisfied with their preceptor role, their likelihood of continuing preceptorship in the future, and reasons for their answers. They showed moderate role satisfaction and likelihood of continuing preceptorship (47\%) and cited improvement of professional knowledge and performance ability as the top reasons for role satisfaction and motivation for preceptorship. Thirty-one percent of respondents replied that they would stop if given the opportunity to stop precepting students due to the high workload (62\%) and insufficient extrinsic rewards (19\%). Additionally, they were asked to rank their perceptions regarding the most valuable benefits of precepting students and were asked how satisfied they were with each benefit. A comparison of preceptors' perceptions and their satisfaction with their real experiences with preceptor benefits showed similar results, with higher rank and satisfaction in improvement of professional knowledge and performance ability and pride regarding professional activities and lower rank and satisfaction with extrinsic compensation (Tables 5 and 6).

The preceptors were asked to rank the top two most valuable incentives, and their responses were compared with the compensation provided by the sites or pharmacy colleges, which were reported by the pharmacy directors. The results of the comparison showed some difference. Respondents ranked monetary compensation $(61 \%)$ and support for education (eg, continuing education; 60\%) as the top two valuable forms of compensation. However, while most of the sites (94\%) received monetary compensation from pharmacy colleges, only $78 \%$ of them provided it to preceptors. Forty-seven percent of the sites simply answered that they supported preceptor education. Among the most valuable compensations, benefit in promotion was ranked fourth (7\%), but the majority of respondents considered it as the second most valuable reward (37\%). However, only one site provided such benefit to preceptors (Table 7).

Based on the results of the univariate analyses, size of the site, location of the site, history of preceptorship, 


\section{American Journal of Pharmaceutical Education 2018; 82 (8) Article 6351.}

Table 3. Participant Demographics Related to Experiential Education $(\mathrm{N}=395)$

\begin{tabular}{|c|c|}
\hline Variables & No. (\%) \\
\hline \multicolumn{2}{|l|}{$\overline{\text { Monetary incentives }}$} \\
\hline Yes & $281(71)$ \\
\hline No & $114(29)$ \\
\hline \multicolumn{2}{|l|}{ Adjunct faculty } \\
\hline Yes & $97(25)$ \\
\hline No & $298(75)$ \\
\hline \multicolumn{2}{|l|}{ Decision to engage in preceptorship } \\
\hline Voluntary & $27(7)$ \\
\hline Compulsory with willingness & $271(69)$ \\
\hline Compulsory without willingness & $97(25)$ \\
\hline \multicolumn{2}{|c|}{ Role in pharmacy practice education (multiple choice) ${ }^{a}$} \\
\hline Preceptor in IPPE & 369 \\
\hline Preceptor in APPE & 128 \\
\hline Coordinator & 46 \\
\hline \multicolumn{2}{|c|}{ Months of precepting per year $(n=368)^{b}$} \\
\hline$\leq 5$ & $169(46)$ \\
\hline $6-9$ & $96(26)$ \\
\hline $10-12$ & $103(28)$ \\
\hline \multicolumn{2}{|c|}{ Hours assigned for precepting per week $(\mathrm{n}=354)^{\mathrm{c}}$} \\
\hline$\leq 10$ & $172(49)$ \\
\hline $10-20$ & $51(14)$ \\
\hline$\geq 21$ & $131(37)$ \\
\hline \multicolumn{2}{|c|}{ Hours spent in one-on-one education per week $(n=354)^{d}$} \\
\hline$\leq 10$ & $249(70)$ \\
\hline $10-20$ & $56(16)$ \\
\hline$\geq 21$ & $49(14)$ \\
\hline \multicolumn{2}{|c|}{ Number of students precepted per year $(n=377)^{\mathrm{e}}$} \\
\hline$\leq 20$ & $202(54)$ \\
\hline $21-50$ & $107(28)$ \\
\hline$\geq 51$ & $68(18)$ \\
\hline \multicolumn{2}{|c|}{ Number of colleges partnered per year $(n=375)^{f}$} \\
\hline$\leq 3$ & $286(76)$ \\
\hline $4-6$ & $46(12)$ \\
\hline$\geq 6$ & $43(12)$ \\
\hline
\end{tabular}

decision to engage in preceptorship, months of precepting per year, hours spent in one-on-one education per week, number of students precepted per year, and preceptor role satisfaction were included in a multivariate regression model to evaluate the factors influencing stress. The number of one-on-one teaching hours spent with students per week and the number of months of precepting per year were identified as positive covariates influencing stress, while preceptor role satisfaction and willingness to engage in preceptorship were identified as negative covariates (Table 8). Regarding satisfaction, final degree, size of the site, monetary incentives, decision to engage in 


\section{American Journal of Pharmaceutical Education 2018; 82 (8) Article 6351.}

Table 4. Ranking of Causes of Stress in the High Stress Group $(\mathrm{N}=258)^{\mathrm{a}}$

\begin{tabular}{lcc}
\hline Items & Rank 1, No. (\%) & Rank 2, No. (\%) \\
\hline Workload & $177(69)$ & $33(13)$ \\
Insufficient support & $27(10)$ & $49(19)$ \\
Self-study burden & $23(9)$ & $39(15)$ \\
Insufficient extrinsic rewards & $15(6)$ & $27(10)$ \\
Stress from students & $10(4)$ & $28(11)$ \\
Difficulty in schedule arrangement & $6(2)$ & $82(32)$ \\
\hline
\end{tabular}

${ }^{a}$ Respondent group who answered that their stress increased from precepting students

preceptorship, months of precepting per year, hours spent in one-on-one education per week, number of students precepted per year, and preceptor role stress were included in a multivariate regression model. Preceptor stress was a significant negative covariate influencing satisfaction, whereas willingness to engage in preceptorship was a positive covariate (Table 8).

Preceptors showed generally high importance and moderate performance in self-assessed preceptor competencies, with a mean of 4.4 for importance and 3.7 for performance. Considering only performance, "expressing enthusiasm for teaching" and "tailoring the contents of the practice education to the level of each student" ranked the lowest with regard to performance and were emphasized as areas in need of improvement. However, the IPA, which reflects the importance and performance of each item, revealed that "expressing enthusiasm for teaching" and "being a role model for practice activities and solving problems" fell within Area A (High Importance/Low Performance), indicating that preceptors need to concentrate on these items for better performance (Figure 1). These results were similar to those revealed in the direct questions to preceptors. Participants were asked whether their competency was sufficient as preceptors and, if not, which among understanding experiential education and performing systematic practice, passion for teaching, professional knowledge and skill, and encouraging and providing constructive feedback they needed to improve upon. Only $36 \%$ of the preceptors responded that they were competent enough to be a preceptor. Ten percent reported that their competency as a preceptor was insufficient, and more than half of them indicated that they lacked the knowledge and skill required to fulfill the role of a preceptor $(57.5 \%)$ or the passion for educating students $(30 \%)$. Additionally, preceptors were asked whether the 8-hour preceptor development program was helpful, to which slightly more than $20 \%$ of the preceptors answered that it helped them perform the role of a preceptor.

Forty-six participants responded to the free-text question. They mostly cited problems pertaining to excessive workload with experiential education, staff shortage and insufficient compensation. They also expressed the need for a practical preceptor training program rather than theoretical education.

Internal consistency reliabilities (Cronbach's alpha) of the questions in the actual survey were acceptable, at 0.82 for the stress items, 0.83 for the benefits of precepting students, 0.94 for the importance of preceptors' competencies, and 0.93 for the performance of preceptors' competencies.

\section{DISCUSSION}

Experiential education is a key element of pharmacy student training and heavily depends on volunteering preceptors. ${ }^{1}$ This study aimed to identify the preceptors' perceptions, the current environment of hospital sites, and to help preceptors improve experiential education under the newly implemented pharmacy education system in South Korea.

Sixty-five percent of respondents answered that their stress increased after joining the new system. The workload was a major cause of precepting-related stress and a major barrier for continuing preceptorship. Workload is

Table 5. Ranking of Preceptors' Views on Benefits of Precepting Students $(\mathrm{N}=395)$

\begin{tabular}{|c|c|c|c|c|}
\hline Item & $\begin{array}{l}\text { Rank 1, } \\
\text { No. (\%) }\end{array}$ & $\begin{array}{l}\text { Rank 2, } \\
\text { No. (\%) }\end{array}$ & $\begin{array}{l}\text { Rank 3, } \\
\text { No. (\%) }\end{array}$ & $\begin{array}{l}\text { Rank 4, } \\
\text { No. (\%) }\end{array}$ \\
\hline Improvement of professional knowledge and performance ability & $230(58)$ & $121(31)$ & $35(9)$ & $9(2)$ \\
\hline Pride regarding professional activities & $127(32)$ & $120(30)$ & $133(34)$ & $15(4)$ \\
\hline Peer recognition & $5(1)$ & $103(26)$ & $113(29)$ & $174(44)$ \\
\hline Extrinsic rewards & $33(8)$ & $51(13)$ & $114(29)$ & $197(50)$ \\
\hline
\end{tabular}


American Journal of Pharmaceutical Education 2018; 82 (8) Article 6351.

Table 6. Satisfaction with Preceptor Benefits Based on Real Experiences ( $\mathrm{N}=395)$

\begin{tabular}{lccc}
\hline Items & $\begin{array}{c}\text { Agree/Strongly } \\
\text { Agree, No. (\%) }\end{array}$ & $\begin{array}{c}\text { Neither Agree nor } \\
\text { Disagree, No. (\%) }\end{array}$ & $\begin{array}{r}\text { Disagree/Strongly } \\
\text { Disagree, No. (\%) }\end{array}$ \\
\hline $\begin{array}{l}\text { Improvement of professional knowledge } \\
\quad \text { and performance ability }\end{array}$ & $247(65)$ & $113(29)$ & $25(6)$ \\
Pride regarding professional activities & $230(58)$ & $123(31)$ & $42(10)$ \\
Peer recognition & $111(28)$ & $126(32)$ & $158(40)$ \\
Extrinsic rewards & $63(16)$ & $156(39)$ & $176(45)$ \\
\hline
\end{tabular}

frequently identified as a challenge for preceptors in teaching students. ${ }^{1,14,16,17}$ Lack of staffing may be one of the reasons for the increase in workload for balancing other responsibilities. A KSHP survey reported that most of the 63 hospitals suffered from pharmacist shortage, and thus, did not meet the number of legally guaranteed pharmacists. ${ }^{11}$ Furthermore, as no pharmacist graduated in 2013-2014, this shortage would have worsened. Therefore, supporting personnel resources may be an important component of decreasing preceptor workload and stress. With most pharmacy graduates practicing in communitybased settings, reconsideration of duration of hospital site rotation in IPPE could be an option to support preceptor workload and stress. Pharmacy students who desire more experience in hospital pharmacy could use APPE consisting of 600 hours. New site enrollment may be another option for decreasing preceptor workload and stress. The number of hospitals with 300 beds or more, which is one of hospital pharmacy site requirements, is more than 160 in South Korea. ${ }^{23}$ However, data for their capacity as education sites is very limited. In-depth research on capacity of non-participating hospital pharmacies should be conducted by college and hospital pharmacy leaders and experiential administrators.

Interestingly, the amount of time preceptors spent in pharmacy practice education was an influential factor for preceptor stress, rather than the number of students they precepted or the number of pharmacy colleges they partnered with. Experience of preceptorship, degree and specialties, and compensation were also not significant influencing factors in preceptor stress, according to this study. Long hours of participation in preceptorship may associate with difficulties pertaining to schedule adjustment and low enthusiasm in precepting, and workload. Skrabal and colleagues reported that teaching consistently throughout the year rather than intermittently can provide an advantage to preceptors and sites among APPE preceptors. ${ }^{17}$ Considering our results, however, preceptor stress increase with continuous experiential education. In light of the different population and education contents, further research related to this issue is warranted.

Another influencing covariant was the willingness to engage in preceptorship, which influenced both preceptor stress and satisfaction. This study revealed that preceptors who were willing to participate in preceptorship, regardless of whether they volunteered to become a preceptor, exhibited lower stress and higher satisfaction compared to those who were unwilling. In addition, $79 \%$ of the respondents (42/53) who did not want to continue preceptorship belonged to the unwilling group. In hospital pharmacies, specialized jobs related to pharmacy practice education are performed by a limited number of pharmacists or just

Table 7. Comparison of Preceptors' Perceptions on Valuable Rewards and Support Offered by the Site or College

\begin{tabular}{|c|c|c|c|c|}
\hline \multirow[b]{3}{*}{ Items } & \multirow{2}{*}{\multicolumn{2}{|c|}{ Preceptors' Perceptions $(\mathrm{N}=395)$}} & \multicolumn{2}{|c|}{ Site Response $(\mathrm{N}=36)^{\mathrm{a}}$} \\
\hline & & & \multirow{2}{*}{$\begin{array}{l}\text { Received Support } \\
\text { from Colleges } \\
\text { No. }(\%)\end{array}$} & \multirow{2}{*}{$\begin{array}{c}\text { Provided Support } \\
\text { to Preceptors } \\
\text { No. }(\%)\end{array}$} \\
\hline & $\begin{array}{c}\text { Rank } 1 \\
\text { No. }(\%)\end{array}$ & $\begin{array}{c}\text { Rank } 2 \\
\text { No. }(\%)\end{array}$ & & \\
\hline Monetary compensation & $187(47)$ & $56(14)$ & $34(94)$ & $28(78)$ \\
\hline Support for education & $135(34)$ & $101(26)$ & $4(11)$ & $17(47)$ \\
\hline Benefit in promotion & $27(7)$ & $147(37)$ & $\mathrm{NA}^{\mathrm{b}}$ & $1(3)$ \\
\hline Academic appointment & $29(7)$ & $54(14)$ & $28(78)$ & NA \\
\hline Benefit in admission of postgraduate & $9(2)$ & $20(5)$ & $1(3)$ & NA \\
\hline Using college resources & $8(2)$ & $17(4)$ & $3(8)$ & NA \\
\hline Support for facilities & NA & NA & $14(39)$ & NA \\
\hline
\end{tabular}

${ }^{\mathrm{a}}$ Multiple choice

${ }^{\mathrm{b}} \mathrm{NA}=$ Not Applicable 


\section{American Journal of Pharmaceutical Education 2018; 82 (8) Article 6351.}

Table 8. Factors Influencing Preceptor Stress and Satisfaction

\begin{tabular}{|c|c|c|c|}
\hline Variables & $\mathbf{B}$ & Standard Error & $p^{\mathbf{a}}$ \\
\hline \multicolumn{4}{|l|}{ Stress $^{\mathrm{b}}$} \\
\hline \multicolumn{4}{|l|}{ Willingness and volunteering for precepting } \\
\hline $\begin{array}{l}\text { Willingness but not volunteering for precepting (reference group non-willingness } \\
\text { and non-volunteering) }\end{array}$ & -.38 & .09 & $<.001$ \\
\hline $\begin{array}{l}\text { Willingness and volunteering for precepting (reference group non-willingness } \\
\text { and non-volunteering) }\end{array}$ & -.43 & .17 & .011 \\
\hline Months of precepting in one year & .04 & .011 & .002 \\
\hline Hours of one-on-one education per week & .01 & .004 & .007 \\
\hline Preceptor role satisfaction & -.12 & .05 & .02 \\
\hline \multicolumn{4}{|l|}{ Satisfaction $^{\mathrm{c}}$} \\
\hline \multicolumn{4}{|l|}{ Willingness and volunteering for precepting } \\
\hline $\begin{array}{l}\text { Willingness but not volunteering for precepting (reference group non-willingness } \\
\text { and non-volunteering) }\end{array}$ & .63 & .10 & $<.001$ \\
\hline $\begin{array}{l}\text { Willingness and volunteering for precepting (reference group non-willingness } \\
\text { and non-volunteering) }\end{array}$ & .74 & .19 & $<.001$ \\
\hline Preceptor stress & -.34 & .30 & $<.001$ \\
\hline
\end{tabular}

${ }^{a}$ Multivariate regression model was applied

${ }^{\mathrm{b}}$ Only statistically significant variables $(p<.05)$ were presented; adjusted for size of the site, location of the site, history of preceptorship, decision to engage in preceptorship, months of precepting per year, hours spent in one-on-one education per week, number of students precepted per year and preceptor role satisfaction; Adjusted $\mathrm{R}^{2}=0.46$

${ }^{\mathrm{c}}$ Only statistically significant variables $(p<.05)$ were presented; adjusted for final degree, size of the site, monetary incentives, decision to engage in preceptorship, months of precepting per year, hours spent in one-on-one education per week, number of students precepted per year, and preceptor role stress; Adjusted $\mathrm{R}^{2}=0.45$

one pharmacist. Pharmacists working in such special jobs might be assigned as preceptors, regardless of their willingness. This result should be considered when designating preceptors to ensure preceptor satisfaction and quality of the experiential education.

Improvement of professional knowledge and performance ability was considered the most important benefit of preceptorship and motivation for precepting students, whereas extrinsic compensation was considered the weakest benefit. These findings are similar to those reported in previous studies reporting that intrinsic benefits outweighed extrinsic rewards. ${ }^{18,19}$

Although extrinsic rewards are seldom a major motivation for preceptorship, insufficient compensation may be a very important reason for discontinuing preceptorship. Skrabal and colleagues reported that $68 \%(38 / 56)$ of their participants indicated that they would not precept students without a monetary stipend. ${ }^{17}$ In our study, insufficient extrinsic compensation was a major reason for discontinuing preceptorship.

Monetary compensation was considered the most valuable incentive, and $71 \%$ of the participants in our study reported that they received such compensation. However, only $16 \%$ of the respondents answered that they were satisfied with the extrinsic rewards they received.
This may associate with the difference between preceptors' views on compensation and the actual compensation provided by sites or colleges; preceptors showed high

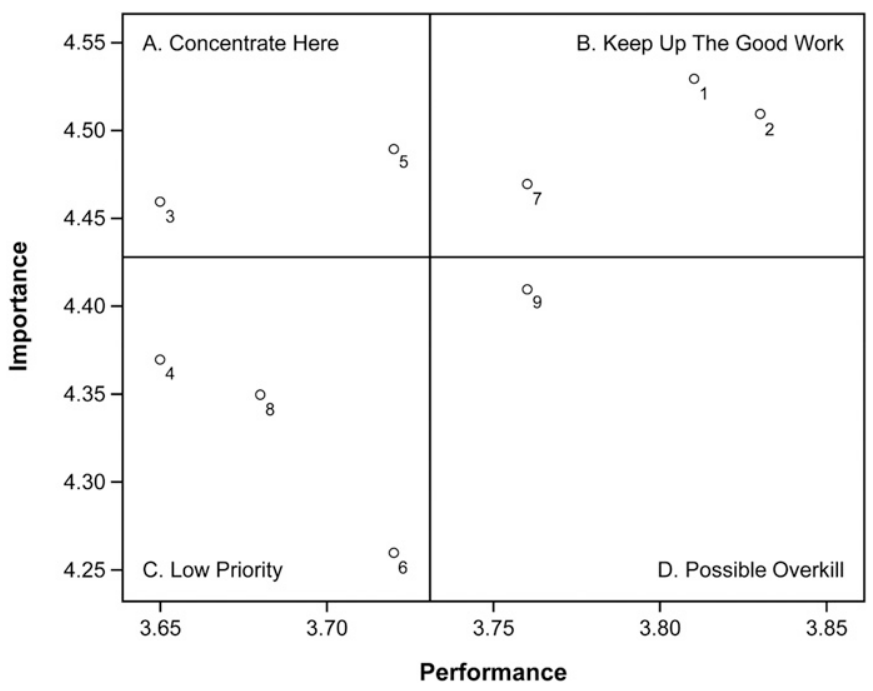

Figure 1. Importance-Performance Analysis (IPA) of Preceptor Competencies. Numbers on the graph refer to the nine preceptor competencies in Table 1. Intersections in the IPA grid are made using total mean importance (4.4) and performance (3.7). Plots are made using each attribute's mean importance and performance. 


\section{American Journal of Pharmaceutical Education 2018; 82 (8) Article 6351.}

preference for receiving support for education and benefit in promotion, while provision of these benefits from the colleges and/or sites was low. Insufficient monetary reward may also relate to low satisfaction of preceptors despite a high monetary compensation rate. Thus, for maintaining and increasing preceptorship adherence, appropriate extrinsic compensation should be considered.

To become a preceptor in South Korea, one must complete practical experience in relevant areas and a preceptor development education. ${ }^{5}$ However, despite these educational requirements, preceptors showed moderate performance and self-confidence in precepting students. All preceptors in this study had graduated from a fouryear pharmacy school and had not received experiential education. In addition, satisfaction regarding the preceptor development program was low, and support for education from sites and/or pharmacy colleges was not considered sufficient. Those factors were associated with the high level of burden on self-study and low performance on professional role model. Based on the low satisfaction pertaining to preceptor development education, appropriate assessments should be conducted, and complementary measures should be implemented. Considering preceptors' background as four-year graduates without experiential education, programs bridging the gap between four- and six-year pharmacists, such as the non-traditional PharmD program offered in the United States and new curriculum-support training in Japan, would help increase preceptors' fundamental skills, knowledge, and self-confidence. ${ }^{23}$

Hospital pharmacists have made an effort to become qualified clinical pharmacists to meet the increasing demand for professional pharmacy services in South Korea. The pharmacy residency program has been implemented in several teaching hospitals in $1983 .{ }^{24}$ Since 2005 , hospital pharmacists have been eligible for the Board of Pharmaceutical Specialties (BPS) certificate that is accredited by the American Pharmacists Association (APhA). ${ }^{25}$ Since 2010, the KSHP has been operating a pharmacist specialty certification program that is similar to that of the BPS. $^{26,27}$ However, physician and nurse specialties are accredited by the Minister of Health and Welfare, whereas pharmacists' specialties are not. ${ }^{28}$ Thus, professional services of pharmacists are rarely supported by medical insurance in South Korea. In addition, the pharmacist manpower requirement in hospital pharmacies is stipulated by the law based on the number of hospitalized patients and prescriptions dispensed for outpatients, and pharmacy technicians are not permitted to dispense prescription medications in South Korea. ${ }^{29}$ Thus, hospital pharmacists are required to spend considerable time dispensing prescription medications. These reasons preclude pharmacists from participating in clinical pharmacist activities. To meet the goals of the newly implemented pharmacy education system and to foster clinical pharmacist participation in public health, policymakers should consider providing support for advanced pharmacy services and clinical pharmacist activities.

This study has some limitations. First, preceptor participation depended on their pharmacy directors; therefore, selection bias may have occurred. Second, only 36 of the 63 hospitals that offered pharmacy practice education participated in this survey; however, the hospital pharmacies that participated were similar to the targeted hospitals in terms of location and size. Third, the preceptors' competencies were self-perceived assessments rather than objective assessments. Therefore, caution should be exercised when trying to generalize findings to the entire population of preceptors. Nevertheless, this study is valuable as a first nationwide survey among hospital pharmacy preceptors in South Korea after the implementation of the new education system. In addition, this study tried to assess experiential education-related wide issues. Thus, the findings could be used as a foundation for future related studies.

For better experiential education, a follow-up study five or more years in the future will be helpful to evaluate the changes in hospital pharmacy practice education and preceptor views regarding pharmacy practice education.

\section{CONCLUSION}

Hospital pharmacy preceptors in South Korea experience high stress, moderate satisfaction and enthusiasm, and moderate self-confidence regarding preceptorship performance. Workload was a major cause of stress and a barrier for continuing preceptorship, while improvement of professional knowledge and performance ability was considered the most important benefit and motivation of preceptorship. The findings will help to enhance the quality of hospital pharmacy experiential education.

\section{REFERENCES}

1. Chaar BB, Brien J-A, Hanrahan J, McLachlan A, Penm J, Pont L. Experimental education in Australian pharmacy: preceptors' perspectives. Pharm Educ. 2011;11:166-171.

2. Paravattil B. Preceptors' self-assessment of their ability to perform the learning objectives of an experiential program. Am J Pharm Educ. 2012;76(9):Article 169.

3. Sonthisombat P. Pharmacy student and preceptor perceptions of preceptor teaching behaviors. Am J Pharm Educ. 2008;72(5):Article 110.

4. Oh JM. The current state of preparation and improvement suggestion of pharmacy practice experience in pharmacy school. J Pharm Policy Res. 2012;7:32-43.

5. Lee BH, Oh JM, Yoon JH. The Manual on the Student Practice Program in the Hospital. Seoul, South Korea: Korean Association of Pharmacy Education; 2013. 


\section{American Journal of Pharmaceutical Education 2018; 82 (8) Article 6351.}

6. Lee JS, Han OY, La HO. An analysis on job stress and job satisfaction of hospital pharmacists working at 8 general hospitals in Korea. J Korean Soc Health Syst Pharm. 2013;30:20-33.

7. Park MS. The current state and problem on hospital labor supply based on change of medical law and countermeasure: the problem of supply of hospital labor and policy. J Korean Hosp Assoc. 2010;39:16-27.

8. Song BW. The current state and countermeasure on supply of hospital pharmacists. J Korean Hosp Assoc. 2008;37:76-88.

9. Lee GW. The current status and future prospects of health care system. Oral presentation presented at: annual meeting of the Korean Society of Health-System Pharmacists, November 2014. Seoul. 10. Lee JH. The current state of preparation and improvement suggestion of pharmacy practice experience in community pharmacy. J Pharm Policy Res. 2012;7:44-52.

11. Kim JH. The current state of hospital pharmacy practice experience. Oral presentation presented at: Pharmacy Leader Workshop of the Korean Society of Health-System Pharmacists; May 2014. Gyeongju. 12. Dillman DA. Mail and Internet Surveys: The Tailored Design Method, with New Internet, Visual and Mixed-mode Guide. Hoboken, NJ: Wiley; 2007.

13. Chang SJ, Koh SB, Kang D, et al. Developing an occupational stress scale for Korean employees. Korean J Occup Environ Med. 2005;17:297-317.

14. Skrabal MZ, Kahaleh AA, Nemire RE, et al. Preceptors' perspectives on benefits of precepting student pharmacists to students, preceptors, and the profession. J Am Pharm Assoc (2003). 2006;46(5):605-612.

15. Alguire PC. Teaching in Your Office: A Guide to Instructing Medical Students and Residents. Philadelphia, PA: American College of Physicians; 2001.

16. Baldor RA, Brooks WB, Warfield ME, O'Shea K. A survey of primary care physicians' perceptions and needs regarding the precepting of medical students in their offices. Med Educ. 2001;35 (8):789-795.

17. Skrabal MZ, Jones RM, Nemire RE, et al. National survey of volunteer pharmacy preceptors. Am J Pharm Educ. 2008;72(5):Article 112.
18. Latessa R, Beaty N, Landis S, Colvin G, Janes C. The satisfaction, motivation, and future of community preceptors: the North Carolina experience. Acad Med. 2007;82(7):698-703. 19. Payakachat N, Ounpraseuth S, Ragland D, Murawski MM. Job and career satisfaction among pharmacy preceptors. Am J Pharm Educ. 2011;75(8):Article 153.

20. Martilla JA, James JC. Importance-performance analysis. $J$ Market. 1977;41(1):77-79.

21. Wong MS, Hideki N, George P. The use of importanceperformance analysis (IPA) in evaluating Japan's e-government services. J Theor Appl Electr Comm Res. 2011;6(2):17-30.

22. Han OY. The 2011 hospital pharmacy factual survey report. Oral presentation presented at: Pharmacy Leader Workshop of the Korean Society of Health-System Pharmacists, May 2012.

23. Yoo S, Song S, Lee S, Kwon K, Kim E. Addressing the academic gap between 4- and 6-year pharmacy programs in South Korea. Am J Pharm Educ. 2014;78(8):Article 149.

24. Park SY, Choi HY, Santoshkumar N-S, Yong CS, Yoo BK. Management and Curricular Components of Pharmacy Residency Programs in Korean Hospitals. J Pharm Soc Korea. 2009;53: 165-172.

25. Korean Society of Health-System Pharmacists. 10 hospital pharmacists passed BPS. http://www.kshp.or.kr/board/n_viw.asp? BrdField=보도자료 \&nbidx = 18365. Accessed May 10, 2016.

26. Kim HS. Pharmacist certification program. J Kor Soc HealthSyst Pharm. 2010;27:359-366.

27. Choi KU. Introduction and development of pharmacist certification program. J Kor Soc Health-Syst Pharm. 2001;18: 208-210.

28. Kim KS, Kim MW. Present and political tasks of advanced practice nurse in Korea. Perspectives in Nursing Science.2009;6: $39-53$.

29. Ministry of Government Legislation. Article 38 of Enforcement Rule of the Medical Service Act: quota of pharmacist and oriental medicine pharmacist in medical institutions. http://law.go.kr/. Accessed February 10, 2017. 